\title{
Cardiac Masses on Cardiac CT: A Review
}

\author{
David Kassop • Michael S. Donovan • \\ Michael K. Cheezum • Binh T. Nguyen • Neil B. Gambill • \\ Ron Blankstein • Todd C. Villines
}

Published online: 17 June 2014

(C) The Author(s) 2014. This article is published with open access at Springerlink.com

\begin{abstract}
Cardiac masses are rare entities that can be broadly categorized as either neoplastic or non-neoplastic. Neoplastic masses include benign and malignant tumors. In the heart, metastatic tumors are more common than primary malignant tumors. Whether incidentally found or diagnosed as a result of patients' symptoms, cardiac masses can be identified and further characterized by a range of cardiovascular imaging options. While echocardiography remains the first-line imaging modality, cardiac computed tomography (cardiac CT) has become an increasingly utilized modality for the assessment of cardiac masses, especially when other imaging modalities
\end{abstract}

This article is part of the Topical Collection on Cardiac Computed Tomography

D. Kassop · M. S. Donovan · T. C. Villines $(\bowtie)$

Cardiology Service, Walter Reed National Military Medical Center, 8901 Wisconsin Avenue, Bethesda, MD 20889, USA

e-mail: todd.c.villines.mil@mail.mil

D. Kassop

e-mail: david.kassop@health.mil

M. S. Donovan

e-mail: michael.s.donovan.mil@health.mil

B. T. Nguyen • N. B. Gambill

Department of Radiology, Walter Reed National Military Medical

Center, 8901 Wisconsin Avenue, Bethesda, MD 20889, USA

B. T. Nguyen

e-mail: binh.nguyen2@med.navy.mil

N. B. Gambill

e-mail: neil.gambill@med.navy.mil

M. K. Cheezum • R. Blankstein

Departments of Medicine and Radiology (Cardiovascular Division),

Brigham and Women's Hospital, Non-Invasive Cardiovascular

Imaging Program, Boston, MA 02115, USA

M. K. Cheezum

e-mail:mcheezum@partners.org

R. Blankstein

e-mail: rblankstein@partners.org are non-diagnostic or contraindicated. With high isotropic spatial and temporal resolution, fast acquisition times, and multiplanar image reconstruction capabilities, cardiac CT offers an alternative to cardiovascular magnetic resonance imaging in many patients. Additionally, cardiac masses may be incidentally discovered during cardiac CT for other reasons, requiring imagers to understand the unique features of a diverse range of cardiac masses. Herein, we define the characteristic imaging features of commonly encountered and selected cardiac masses and define the role of cardiac CT among noninvasive imaging options.

Keywords Cardiac computed tomography $\cdot$ Coronary computed tomographic angiography $\cdot$ Cardiac mass . Neoplasm $\cdot$ Tumor $\cdot$ Myxoma $\cdot$ Lipoma $\cdot$ Teratoma . Sarcoma $\cdot$ Metastasis $\cdot$ Thrombus $\cdot$ Pericardial cyst

\section{Introduction}

Cardiac masses are uncommon findings and can be categorized as either neoplastic or non-neoplastic (Table 1). Neoplastic cardiac masses are comprised of primary benign tumors, primary malignant tumors, or metastatic tumors. Primary cardiac tumors are exceedingly rare with a reported prevalence of 0.001 to $0.03 \%$ in an autopsy series, while metastatic tumors to the heart are reported to be 20 to 40 times more common [1]. Of all cardiac tumors that originate in the heart (primary), approximately $75 \%$ are benign, with myxoma accounting for at least half of reported cases $[1,2]$. The remaining $25 \%$ of primary cardiac tumors are malignant with sarcoma accounting for a majority of reported cases [3]. Nonneoplastic cardiac masses, such as thrombi, pericardial cysts, and prominent anatomic structures, can often mimic cardiac tumors. The evaluation of cardiac masses may therefore be a diagnostic challenge. 
Table 1 Cardiac neoplasms and commonly-encountered non-neoplastic masses

\begin{tabular}{|c|c|}
\hline Cardiac masses & Type \\
\hline Benign tumors & $\begin{array}{l}\text { Myxoma } \\
\text { Lipoma } \\
\text { Papillary fibroelastoma } \\
\text { Fibroma } \\
\text { Hemangioma } \\
\text { Paraganglioma } \\
\text { Teratoma } \\
\text { Atrioventricular (AV) nodal mesothelioma } \\
\text { Rhabdomyoma }\end{array}$ \\
\hline Malignant tumors & $\begin{array}{l}\text { Metastatic } \\
\text { Angiosarcoma } \\
\text { Rhabdomyosarcoma } \\
\text { Fibrosarcoma } \\
\text { Lymphosarcoma } \\
\text { Osteosarcoma } \\
\text { Liposarcoma } \\
\text { Mesothelioma }\end{array}$ \\
\hline Non-neoplastic & $\begin{array}{l}\text { Lipomatous hypertrophy of interatrial septum } \\
\text { Intracardiac thrombus } \\
\text { Pericardial cyst } \\
\text { Large coronary artery aneurysm } \\
\text { Valvular vegetation } \\
\text { Crista terminalis }\end{array}$ \\
\hline
\end{tabular}

\section{Imaging Approach to Cardiac Masses}

Noninvasive imaging plays a critical role in the diagnosis and surgical planning of cardiac masses. Furthermore, certain characteristics identified on imaging may help distinguish neoplastic versus non-neoplastic masses and benign versus malignant tumors (Table 2). Despite the versatility and high accuracy of cardiac computed tomography (cardiac CT) and cardiac magnetic resonance (MR) imaging, echocardiography remains the first-line for cardiac mass evaluation because of its widespread availability, lack of iodinated contrast material or radiation exposure, and its dynamic assessment of cardiac masses in relation to the surrounding chambers, valves, and pericardium. However, echocardiography provides limited assessment of soft-tissue characteristics and extracardiac structures and may be limited by poor acoustic windows, particularly in obese patients and those with chronic lung disease $\left[4^{\bullet}\right]$.

Cardiac CT and MR are often utilized synergistically with echocardiography in the evaluation and management of cardiac masses. Appropriate Use Criteria for cardiac MR [5] and cardiac CT [6] and an Expert Consensus statement for pericardial disease imaging $[7 \bullet \bullet$ ] provide specific guidance on the approach to cardiac masses (Table 3). Cardiac MR is often the preferred imaging modality for cardiac masses because of its superior soft-tissue characterization, high temporal resolution, multiplanar imaging capabilities, and unrestricted field of view [8]. Since MR does not require the use of ionizing radiation, it is the modality of choice, along with echocardiography, for pediatric patients with cardiac masses. However, cardiac MR is dependent on patient cooperation to obtain quality images and is specifically contraindicated in patients with claustrophobia and implanted magnetic devices. At times, MR may also be limited for evaluating small mobile masses (e.g., papillary fibroelastoma or valvular vegetations) due to limitations in spatial resolution and typically does not provide detailed assessment of the coronary arteries in cases where the assessment of coronary artery disease prior to surgery is an important clinical question.

Cardiac CT is an alternative imaging modality to assess cardiac masses, particularly in patients with known contraindications to MR or in patients with inadequate images from other noninvasive methods. Cardiac $\mathrm{CT}$ is a fast imaging technique with electrocardiographic (ECG) gating that provides high quality images with superior spatial resolution.
Table 2 Cardiac CT features of benign and malignant tumors

\begin{tabular}{lll}
\hline Feature & Benign & Malignant \\
\hline Size/number & Small $(<5 \mathrm{~cm})$, single lesion & Large $(>5 \mathrm{~cm})$, multiple lesions \\
Location & Left $>>$ right & Right $>>$ left \\
Morphology & Intracameral & Intramural \\
Attachment & Narrow stalk, pedunculated & Broad base \\
Enhancement & Absent to minimal & Modest to intense \\
Margin & Smooth, well-defined & Irregular, ill-defined \\
Invasion & None & Intra-/extracardiac infiltration \\
Metastasis & None & May be present \\
Pericardial effusion & None & May be present \\
Calcification & Rare (except for small foci in fibroma, & Large foci in osteosarcoma \\
& myxoma, or teratoma) & \\
\hline
\end{tabular}


Electrocardiographic gating minimizes motion-related artifacts and allows a more precise delineation of the lesion margins. Compared to other cardiac imaging modalities, CT is optimal for the evaluation of calcified masses, the global assessment of the chest and lung tissue and corresponding vascular structures, and the exclusion of obstructive coronary artery disease or masses which involve the coronary arteries. Significant disadvantages with CT include radiation exposure, a small risk of contrast-induced nephropathy, and lower soft tissue and temporal resolutions as compared with magnetic resonance imaging.

Cardiac CT is also useful to detect metastases in suspected malignancies especially when coupled with ${ }^{18} \mathrm{~F}$ fluorodeoxyglucose (FDG) positron emission tomography (PET). The ability of ${ }^{18} \mathrm{~F}$-FDG PET/CT to detect the increased metabolism of glucose may help distinguish malignancy from a benign neoplasm. For example, primary malignant cardiac tumors and metastatic tumors show significantly higher glucose uptake as quantified by ${ }^{18} \mathrm{~F}$-FDG PET/CT standardized uptake value (SUV) than primary benign cardiac tumors. This differentiation may improve the detection of distant metastases, especially when the results will be used to impact therapy [9•].

The formulation of a differential diagnosis for cardiac masses on cardiac CT is based on several key aspects. They include size, quantity, location (cardiac chamber, pericardial involvement, extracardiac structures), morphology (attachment, margin appearance, infiltration), tissue characteristics (calcification, fat attenuation, vascularity), and clinical correlation (known malignancy or infection, presence of a catheter, associated syndromes) (Table 4). When performed to assess for cardiac masses, specific CT protocols unique from those typically utilized for coronary imaging can be implemented to obtain high quality images. For example, right atrial or right ventricle masses may require a right heart contrast injection protocol with multiphasic contrast administration to obtain optimal images. Additionally, low dose non-contrast and delayed CT imaging may be helpful in distinguishing intracardiac thrombus from tumor and to detect calcifications. Clinical and imaging features of primary cardiac masses are summarized in Table 2.

\section{Benign Cardiac Neoplasms}

\section{Myxoma}

Myxoma is the most common primary cardiac tumor, accounting for $25-50 \%$ of cases. It typically affects middle-aged adults, 30-60 years of age, with a higher prevalence in women [10]. A majority (60-75\%) of cases are located in the left atrium attached to the fossa ovalis by a thin stalk, though less common locations include the right atrium (15-20\%), inferior vena cava, ventricles, and the valve leaflets [11]. Myxomas are solitary tumors that have a low risk of recurrence following surgical resection. However, multiple myxomas and myxomas with an atypical location have a higher risk of recurrence. These are more common in younger men and in several familial syndromes accounting for $10 \%$ of cases $[12,13]$ :

- Carney complex: multiple recurrent cardiac and mucocutaneous myxomas, pigmented skin lesions, schwannomas, and endocrine overactivity neoplasms.

- $L A M B$ : Lentigines, Atrial Myxoma, and Blue nevi.

- NAME: Nevi, Atrial myxoma, Myxoid neurofibroma, and Ephelides.

On cardiac CT, approximately two-thirds of myxomas are ovoid with a smooth or lobular shape, with the remainder villous in appearance. When visualized on non-contrast $\mathrm{CT}$, they typically appear hypodense, consistent with blood, and may demonstrate calcifications more often in the right atrial location (Fig. 1). On contrast-enhanced cardiac CT, myxomas appear as intracavitary filling defects with heterogeneous contrast enhancement, though the intensity may be variable depending on their chronicity and whether necrosis or hemorrhage is present. Often mobile on cine ECG gated imaging, myxomas may prolapse across the atrioventricular valves causing outflow tract obstruction depending on their size and location. When symptoms or peripheral emboli occur, surgical removal is often required.

\section{Lipoma}

Lipoma is the second most common primary benign tumor and accounts for approximately $10 \%$ of primary cardiac tumors [8]. Lipomas commonly occur in middle-aged and older adults. Lipomas are encapsulated, well-circumscribed tumors consisting of mature adipocytes that can occur anywhere in the heart (Fig. 2). Approximately $50 \%$ arise in the epicardial or mid-myocardial layers, while the other half are subendocardial, where they create filling defects with a homogenous appearance of fat attenuation (density $<-50$ Hounsfield units $[\mathrm{HU}])$. They can occasionally be visible as thin septations on cardiac CT. Although most are solitary tumors, multiple cardiac lipomas can occur and have been described in patients with tuberous sclerosis [10]. Classically, lipomas are benign and slow growing, but depending on their location, lipomas may rarely cause a variety of complications to include compression of the coronary arteries or pericardial space (subepicardial), outflow obstruction (subendocardial), or arrhythmias (intra-myocardial).

\section{Papillary Fibroelastoma}

Papillary fibroelastoma is the third most common primary benign cardiac tumor with an incidence of up to $0.33 \%$ in 
Table3 Recommendations for the use of noninvasive imaging to evaluate suspected cardiac and pericardial masses

$\mathrm{CT}$, computed tomography; MRI, magnetic resonance imaging

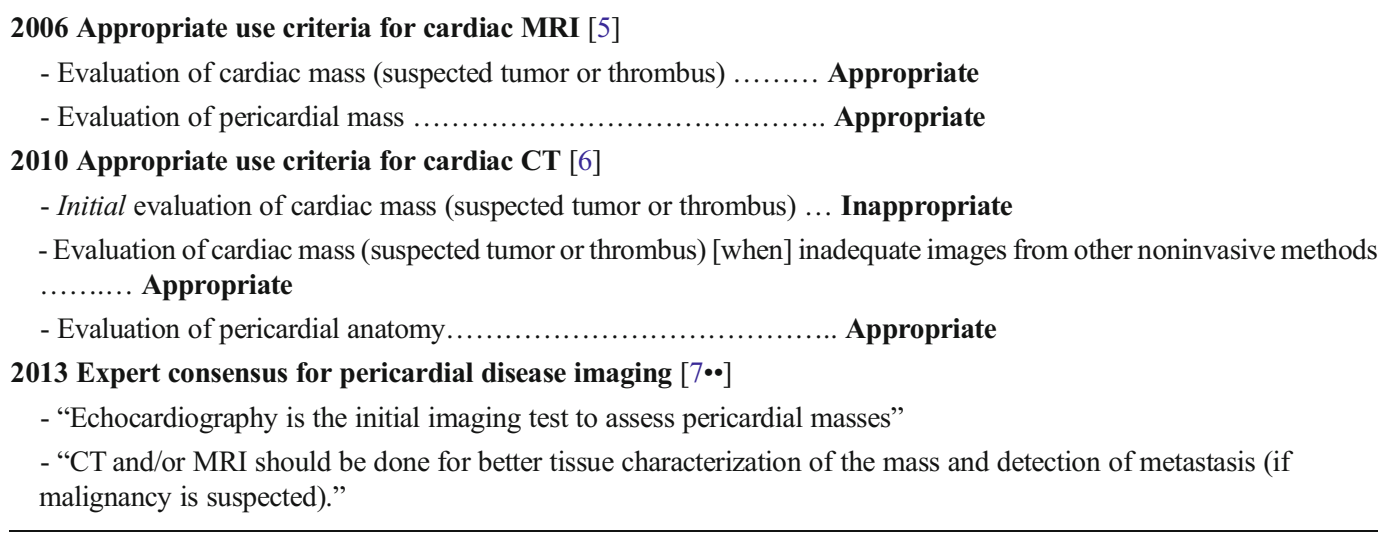

autopsy series [14]. Papillary fibroelastomas account for approximately $75 \%$ of all cardiac valvular tumors and affect men and women equally with a mean age of 60 years [15]. They are characterized by a collection of avascular fronds of dense connective tissue lined by endothelium and may arise from any endocardial surface, though the majority are found on the aortic and mitral valves. Most papillary fibroelastomas are solitary and small with an average diameter of $10 \mathrm{~mm}$. However, some are mobile with a stalk and appear more likely to give rise to embolism [14]. Though most patients are asymptomatic, patients may experience cerebral embolic symptoms, such as transient ischemic attacks or strokes, or angina from coronary ostial obstruction from aortic valve lesions. Echocardiography is the preferred means for evaluation. Papillary fibroelastomas may be difficult to identify on cardiac CT due to their small size, pronounced mobility, and lack of calcification. If visible in cardiac CT, papillary fibroelastomas appear hypodense with irregular borders attached by a thin stalk (Fig. 3) and mobile on cine ECG gated imaging.

\section{Teratoma}

Cardiac teratoma is a rare, primary benign germ cell tumor that typically affects infants and children. Over $90 \%$ of cardiac teratomas involve the pericardium with

Table 4 Cardiac CT features of primary cardiac tumors

\begin{tabular}{|c|c|c|}
\hline Tumor & Location & Cardiac CT findings \\
\hline \multicolumn{3}{|l|}{ Benign (75\%) } \\
\hline Myxoma & $\mathrm{LA}>\mathrm{RA}$, ventricles & $\begin{array}{l}\text { Pedunculated, mobile, heterogeneous, low attenuation, } 10 \% \text { calcified; may } \\
\text { prolapse through the mitral valve }\end{array}$ \\
\hline Lipoma & Varies & $\begin{array}{l}\text { Smooth, encapsulated, fat attenuation, no enhancement; multiple lesions may } \\
\text { be seen with tuberous sclerosis }\end{array}$ \\
\hline Fibroelastoma & Valves & Small $(10 \mathrm{~mm})$, smooth, pedunculated, mobile \\
\hline Rhabdomyoma & $\mathrm{LV}>\mathrm{RV}$ & Smooth, multiple, attenuation similar to myocardium; $>90 \%$ in infants and children \\
\hline Fibroma & $\mathrm{LV}>\mathrm{RV}$ & $\begin{array}{l}\text { Homogenous, low attenuation, minimal enhancement, central calcification; second } \\
\text { most common in infants and children }\end{array}$ \\
\hline Hemangioma & $\mathrm{LV}>\mathrm{RV}$ & Heterogeneous, intense enhancement \\
\hline Teratoma & Pericardium & Multicystic, moderate enhancement, partially calcified \\
\hline \multicolumn{3}{|l|}{ Malignant (25 \%) } \\
\hline Angiosarcoma & $\mathrm{RA}>\mathrm{RV}$, pericardium & $\begin{array}{l}\text { Broad base, irregular, heterogeneous, low attenuation, infiltrative, pericardial effusion, } \\
\text { metastatic }\end{array}$ \\
\hline Rhabdomyosarcoma & Myocardium, valves & Irregular, low attenuation, infiltrative; most common in infants and children \\
\hline Fibrosarcoma & LA, pericardium & Large, irregular, low attenuation, central necrosis, infiltrative \\
\hline Osteosarcoma & $\mathrm{LA}>\mathrm{RA}, \mathrm{RV}$ & Broad base, low attenuation, infiltrative, extensive calcification \\
\hline Liposarcoma & $\mathrm{LA}>\mathrm{RA}$, pericardium & Large, fat and soft tissue attenuation, mild contrast enhancement, infiltrative \\
\hline Mesothelioma & Pericardium & Infiltrative, variable attenuation, pericardial effusion \\
\hline
\end{tabular}

LA, left atrium; LV, left ventricle; RA, right atrium; RV, right ventricle 

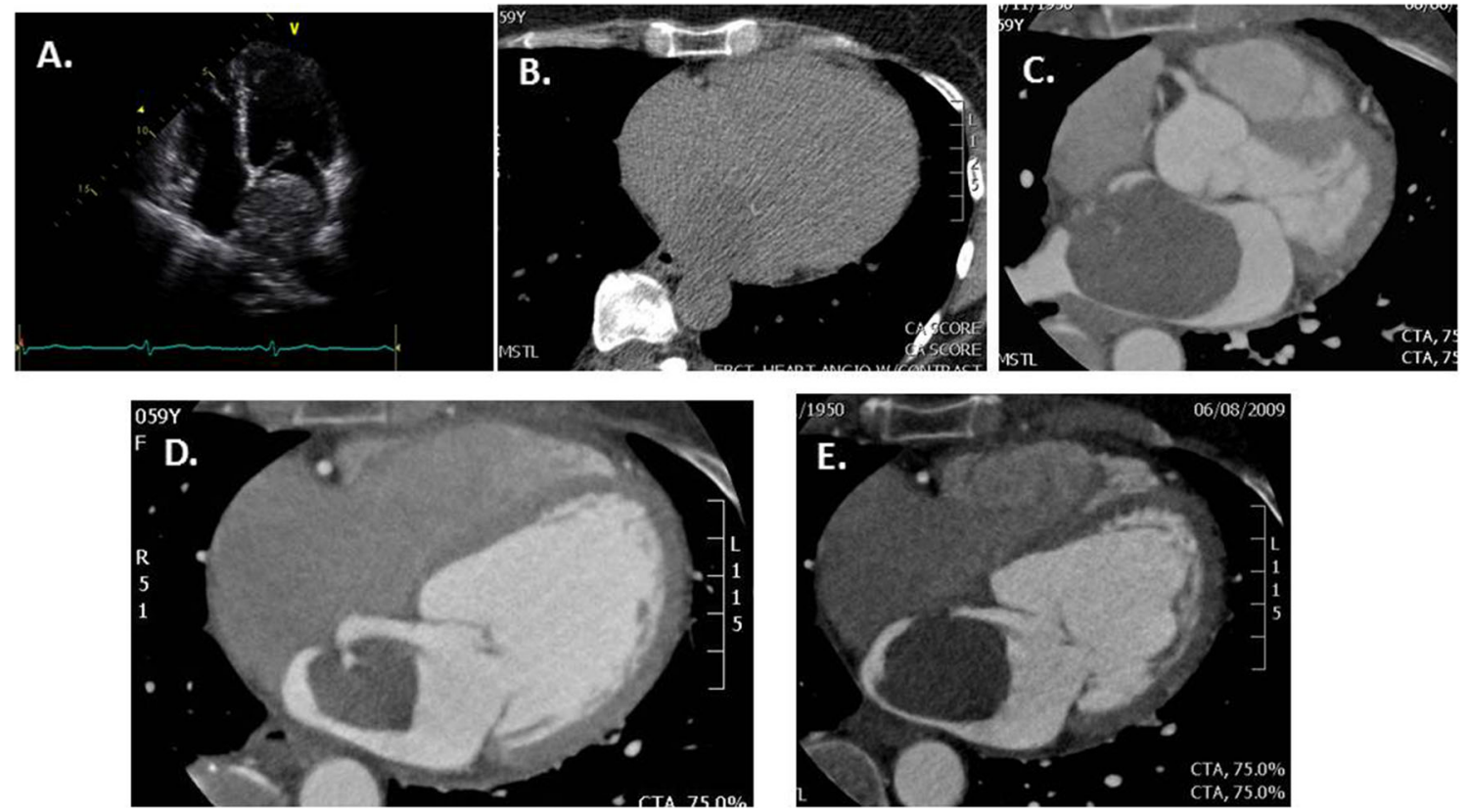

Fig. 1 Atrial myxoma. (a) Apical four-chamber view on transthoracic echocardiogram demonstrating a large mass occupying the majority of the left atrial cavity. (b) Non-contrast axial image faintly demonstrating the large left atrial mass. (c-e) Cardiac CT angiography images

demonstrating a large, low attenuating mass with a small stalk attached to the fossa ovale, consistent with a large left atrial myxoma. Note the patchy, non-homogenous contrast enhancement

a predilection for pericardial effusions resulting in tamponade and/or compression of right-sided vascular structures (superior vena cava, right atrium, and pulmonary artery) $[1,2]$. Cardiac teratomas contain derivatives of all three germ layers, with mature endodermal, mesodermal, and neuroectodermal elements [2]. On CT, they appear as multicystic, heterogeneous tumors typically with an associated pericardial effusion (Fig. 4) [16]. Lipid or calcific densities can also be present on CT which often provide useful clues to the diagnosis. Cardiac CT may demonstrate their intrapericardial location, extent, and relation to

vascular structures to which they are adherent, assisting planned surgical interventions [16].

\section{Malignant Cardiac Neoplasms}

\section{Metastatic Tumors}

Malignant cardiac tumors are most often a result of metastatic disease arising by direct extension of adjacent organs or

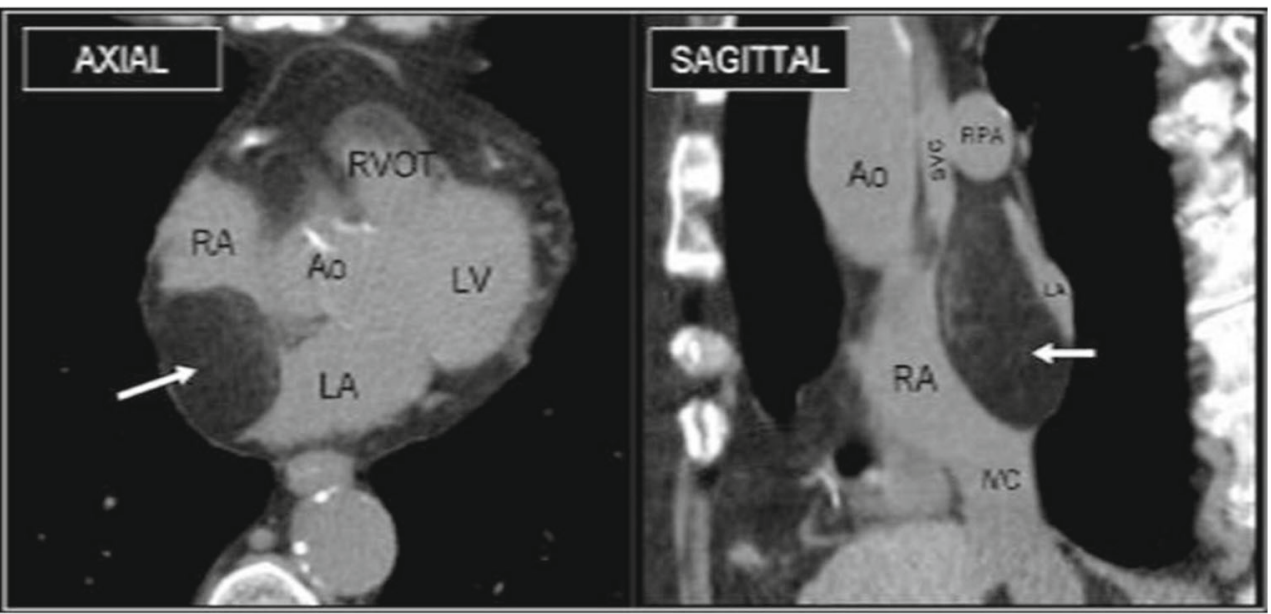

Fig. 2 Lipoma. Non-gated MDCT images in the axial and sagittal oblique planes from a 65 -year-old female incidentally demonstrate a fatty mass in the posterior and superior region of the interatrial septum consistent with an interatrial lipoma (arrow). Right atrium (RA), Right ventricular outflow tract (RVOT), Left atrium (LA), Left ventricle (LV), Aorta (Ao) Superior vena cava (SVC), Right pulmonary artery (RPA). * Reproduced with permission from [17] 

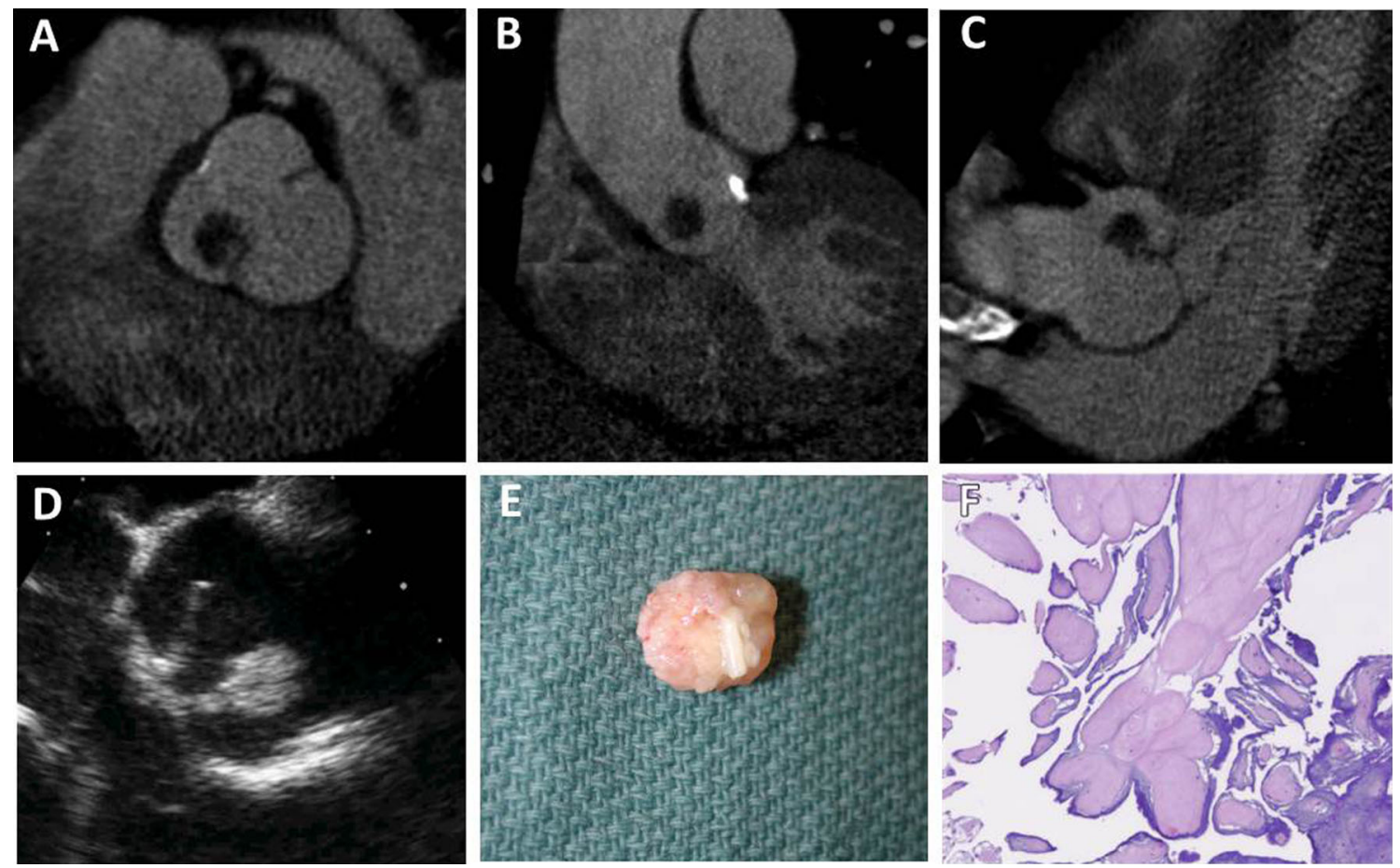

Fig. 3 Papillary fibroelastoma. CCT demonstrates a hypodense, microlobulated mass attached via a short stalk to the aortic valve on the aortic surface of the right coronary cusp (a-c). A transesophageal echocardiogram (TEE), mid-esophageal short-axis view of the aortic root, demonstrates a mobile echodense mass attached to the right coronary

spread via hematogenous, lymphatic, or intracavitary routes [1]. The most common malignancies metastatic to the heart originate from the lung $(35-40 \%)$, followed by breast $(10 \%)$ and hematologic (10-20\%) carcinomas. Melanoma has the greatest propensity to metastasize to the heart, but it is often found late in the disease process $[18 \bullet]$. Other primary sites of origin include renal, hepatic, adrenal, and thyroid. The most frequent location of metastasis is the pericardium (65-70\%), followed by epicardium (25-35\%) and myocardium (30\%). Endocardial or intracavitary involvement is rarely observed (3.5\% of cases) $[18 \cdot]$.

Cardiac CT offers several advantages for the evaluation of metastatic cardiac involvement. Primarily, cardiac CT offers cusp (d). Gross examination following resection revealed a $1.1 \times 1.3 \times$ $1.2 \mathrm{~cm}$ tan-pink, friable, soft mass with a short stalk and a micronodular appearance, a typical feature for fibroelastoma (e). Histopathology of the mass demonstrates an avascular core surrounded by a loose matrix with multiple adjacent fronds covered by endothelium (f)

the ability to image direct tumor extension and extracardiac involvement with both three-dimensional reconstruction capability and superior spatial resolution. On cardiac CT, pericardial metastasis can appear as pericardial thickening, disruption, or effusion. Myocardial involvement typically demonstrates thickening and nodularity. Solid tumors often demonstrate enhancement following the administration of intravenous contrast.

\section{Angiosarcoma}

Angiosarcoma is the most common primary cardiac malignant tumor and is comprised of cells that develop multiple,
Fig. 4 Teratoma. a.

Posteroanterior chest radiograph demonstrating a mass in the aortopulmonary window (arrow). b. Contrast non-gated axial CT image demonstrating a cystic pericardial mass. Subsequent cardiac MR suggested possible solid components atypical for a simple pericardial cysts. Pathological analysis postresection identified the mass as a teratoma
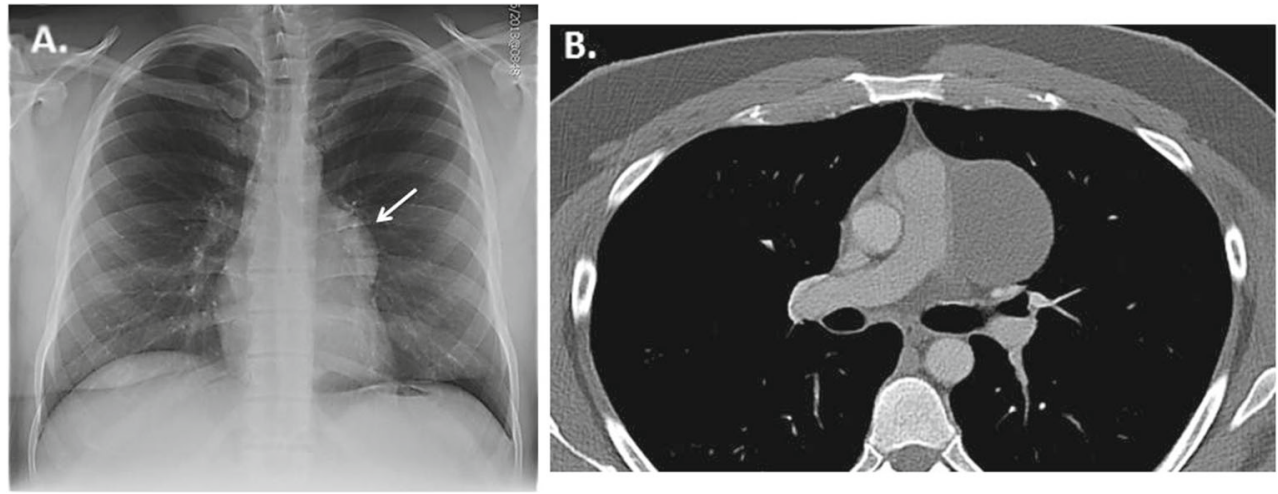
irregular vascular channels. The primary site of origin is the right atrial free wall in $80 \%$ of cases and less commonly the right ventricle or pericardium [19]. The tumor morphology typically consists of a large, multilobar mass with a heterogeneous composition that spreads along the epicardial surface and replaces the right atrial wall. Given the bulky nature, the tumor may comprise the majority of the right atrium and involve the right coronary artery leading to rupture [20]. These tumors may also be localized to the pericardium and often invade adjacent cardiac structures leading to cardiomegaly and recurrent pericardial effusions [21].

Cardiac CT allows evaluation of the tumor burden and vascularity to help distinguish this rare malignant tumor (Fig. 5). The tumor typically is characterized by a broadbased attachment with a hematogeneous connection between the right atrium and the tumor cavity which may often be identified on early imaging. Delayed imaging allows for better visualization of the tumor cavity given late contrast enhancement. The tumor is grossly hemorrhagic and often heterogeneous in appearance given the scattered areas of nonenhancing necrosis. Additionally, invasion to adjacent structures including the myocardium, pericardium, mediastinum, great vessels, and pulmonary metastasis may be identified. With pericardial involvement, there is usually "sheet-like" thickening due to the distribution and arrangement of tumor cells, in contrast to the nodular appearance seen with rhabdomyosarcomas. Pericardial and pulmonary effusions are also readily observed.

\section{Rhabdomyosarcoma}

Rhabdomyosarcoma is the second most common primary malignant tumor. It accounts for $4-7 \%$ of cardiac sarcomas and remains the most common pediatric cardiac malignancy [1]. It is a malignant tumor of striated muscle that always involves the myocardium. In contrast to angiosarcomas, rhabdomyosarcomas may arise from any location with no predilection for a specific cavity as $60 \%$ of cases involve multiple sites of origin [22]. Additionally, the tumors may invade the pericardial space with a characteristic nodular appearance [23].

Rhabdomyosarcomas appear as large, infiltrative masses that may surround a central area of necrosis on cardiac CT (Fig. 6). They may invade the epicardial fat, valves, or surrounding myocardium. The masses are intracavitary with irregular borders and low attenuation that may appear as thickening of the myocardium [10]. They may also appear as a hemorrhagic mass replacing the pericardium. Cardiac $\mathrm{CT}$ is useful for identifying any extracardiac extension of the tumor as well as distant metastasis, common to the lung parenchyma, thoracic lymph nodes, mediastinum, or spine [22].

\section{Non-Neoplastic Cardiac Masses}

Lipomatous Hypertrophy of the Interatrial Septum

Lipomatous hypertrophy of the interatrial septum (LHIAS) is an increasingly recognized, benign incidental finding with a prevalence of $1-8 \%$ in the general population [24]. Incidence increases with age and body mass index. It occurs more frequently in women and those with a history of systemic steroid use [24]. Findings consistent with LHIAS on cardiac CT include a "dumbbell-shaped" mass involving the interatrial septum with sparing of the fossa ovalis, a
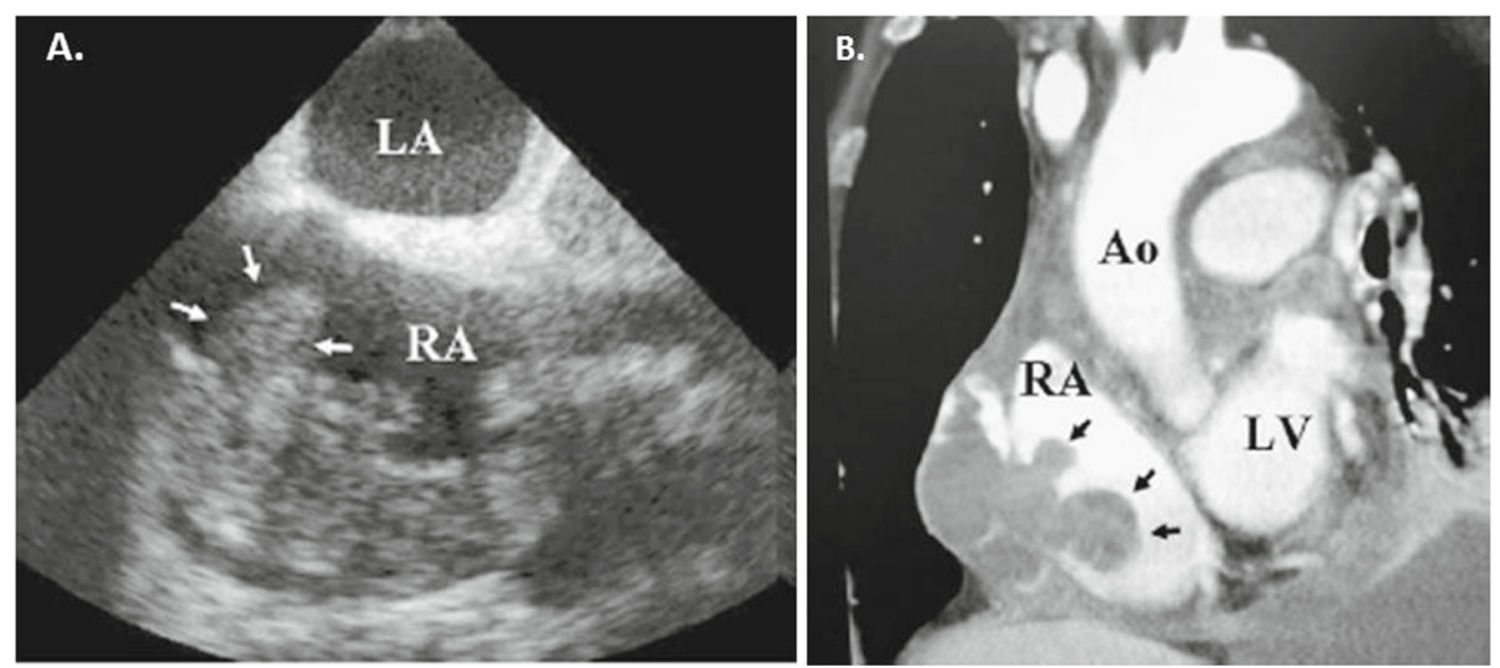

Fig. 5 Angiosarcoma. a. Transesophageal echocardiogram demonstrating a large, lobulated mass in the right atrium. b. Contrast non-gated cardiac CT demonstrating a hypodense, multilobular mass in the right atrium. The mass invaded into the pericardial space. Aorta (Ao), Left atrium (LA), Left ventricle (LV), Right atrium (RA) 

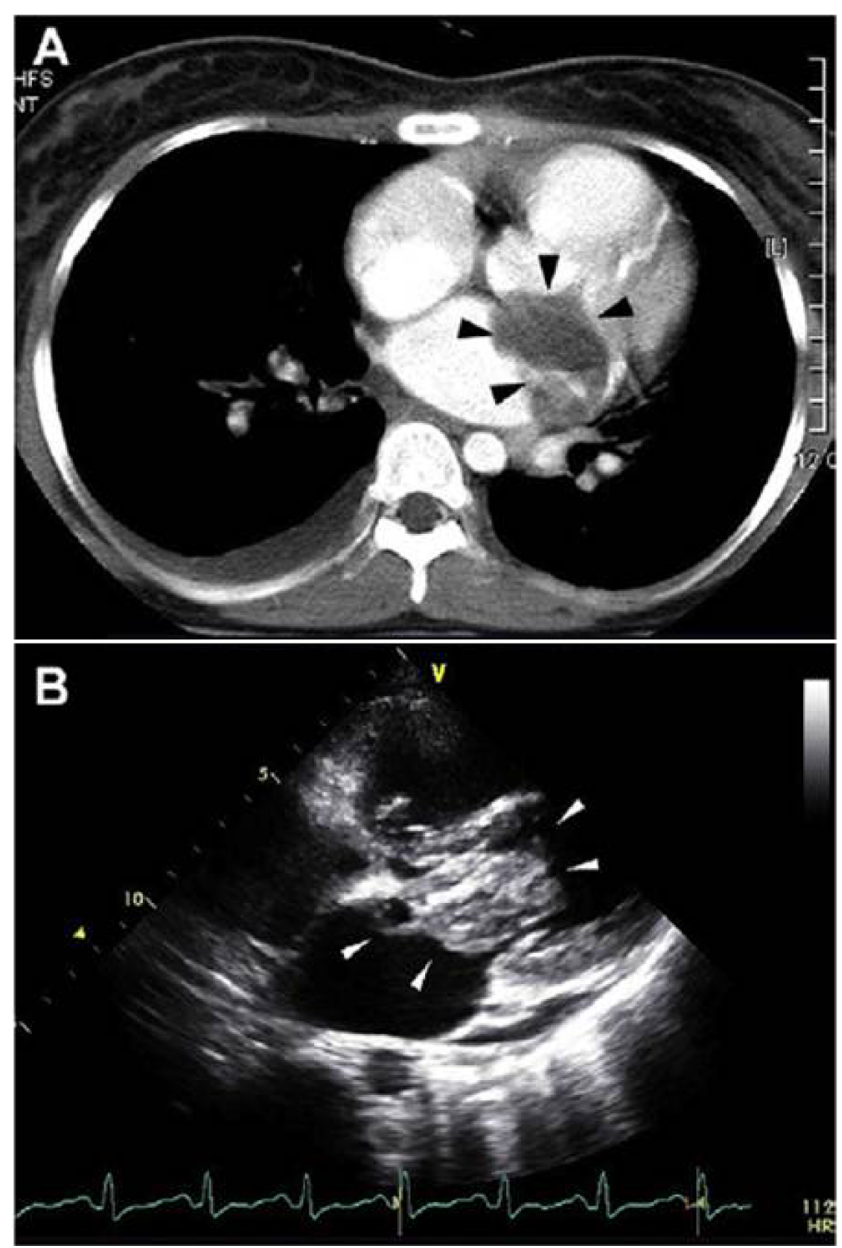

Fig. 6 Rhabdomyosarcoma. a. Non-gated contrast CT demonstrating a large mass in the left atrium with heterogenous contrast enhancement (black arrows). b. Transthoracic echocardiogram demonstrates a large mass involving the mitral valve apparatus. Pathology was consistent with a rhabdomyosarcoma. *Reproduced with permission from [25]

homogenous appearance with sharp margins, fatty attenuation (density<-50 HU), and no or minimal contrast enhancement (Fig. 7). Lipomatous hypertrophy of the interatrial septum typically follows a benign course though associations with supraventricular arrhythmias, sudden cardiac death, and extensive impairment on venous return requiring surgical resection have been described $[24,26]$.

Although there is no definitive diagnostic criteria for the diagnosis of LHIAS, an interatrial septal thickness $>20 \mathrm{~mm}$ is often used, while a septal thickness exceeding $30 \mathrm{~mm}$ may have a greater association with supraventricular arrhythmias [27]. It is important to note that areas of lipomatous hypertrophy contain brown fat and, therefore, may appear as FDG-avid ("hot") on PET scans. Though rare, liposarcoma should be considered as a differential diagnosis, especially when intra-mass calcification or enhancement is present or in cases with rapid growth and involvement beyond the interatrial septum. Other causes of fat

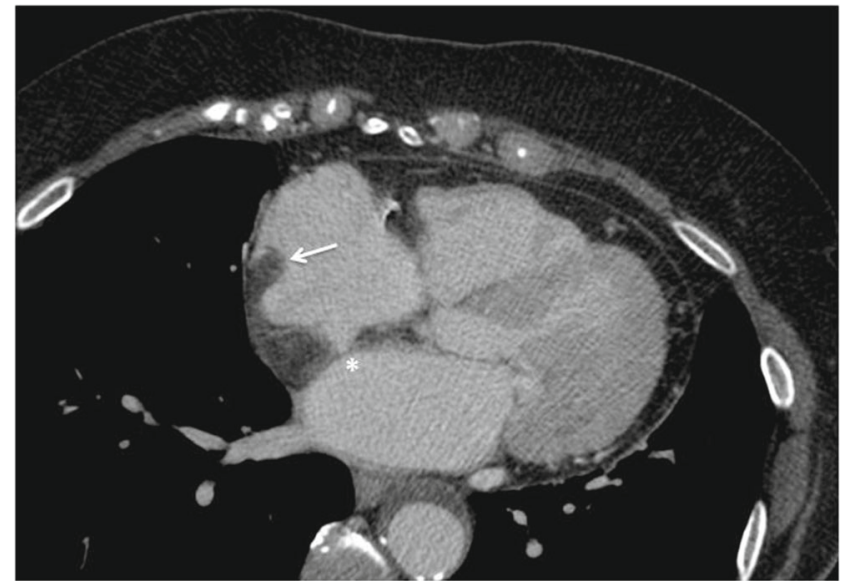

Fig. 7 Lipomatous hypertrophy of the interatrial septum. Cardiac CT demonstrating a mass with fat-attenuation which spares the fossa ovalis (*) consistent with lipomatous hypertrophy of the interatrial septum. Note that the mass also extends to involve the posterior wall of the right atrium and crista terminalis (arrow), which may be seen in cases of more extensive lipomatous hypertrophy

containing cardiac lesions include fatty metaplasia due to remote myocardial infarction, cardiac lipoma and arrhythmogenic right ventricular cardiomyopathy/dysplasia.

\section{Intracardiac Thrombus}

Thrombus accounts for the most commonly encountered intracardiac mass [28]. It can occur in any of the cardiac chambers, though it most often involves the left-sided structures. Thrombus formation can be caused by hypercoagulable states, systolic dysfunction with wall motion abnormalities, atrial fibrillation, or artificial devices. It typically appears as a hypodense, lowattenuation filling defect in a contrast pool within a cardiac chamber and may be differentiated from primary and secondary tumors by knowledge of predisposing risk factors, attachment location, shape, and lack of mobility [29•].

Cardiac CT has very high sensitivity for excluding thrombus of the left atrial appendage but findings of low attenuation in the left atrial appendage (LAA) are not specific to thrombus as this often represents circulatory stasis, an incomplete mixing of contrast material and blood. This "pseudo" filling defect may mimic thrombus, especially in low-flow states [30•]. However, delayed imaging of the LAA may significantly improve the specificity to distinguish thrombus from circulatory stasis [31]. For example, a ratio of LAA attenuation to the ascending aorta $>0.75$ on delayed cardiac CT images performed 30 seconds following first-pass contrast imaging can help differentiate thrombus from circulatory stasis with a high negative predictive value [32].

Left ventricular thrombi are often located in an area of myocardial hypokinesis, dyskinesia or aneurysm formation. They are frequently crescent-shaped filling defects with broad based attachments (Fig. 8). However, a pedunculated 
Fig. 8 Left ventricular thrombus. Curved multiplanar image demonstrating a severe stenosis in the ostial portion of the left anterior descending artery (arrow) due to non-calcified plaque. $\mathbf{b}$. Axial image from the same patient demonstrating a large hypodensity in the left ventricular apex consistent with thrombus
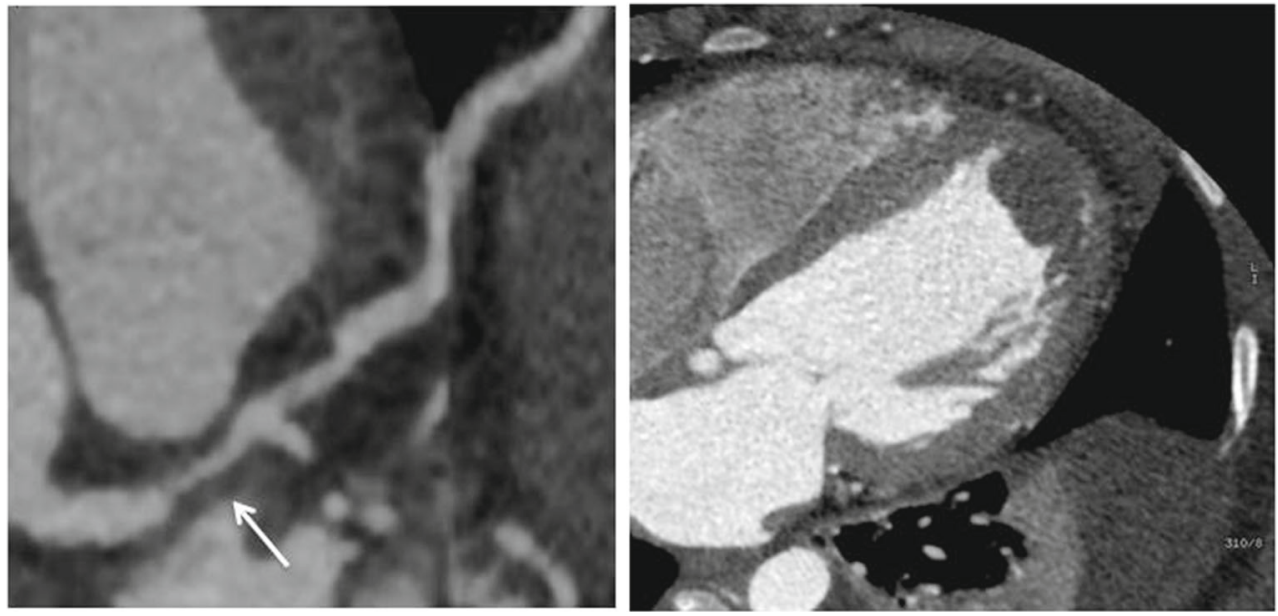

appearance has been observed and can mimic myxoma [33]. Chronic thrombi may develop spotty calcifications, though this feature has not been shown to significantly differentiate thrombus from myxoma. Thrombus within the left ventricle may be distinguished from myocardium by lower attenuation characteristics with a threshold of $65 \mathrm{HU}$ providing a sensitivity and specificity of $94 \%$ and $97 \%$, respectively [29•]. Right ventricular thrombus is a rare finding and usually associated with intravenous catheters, pulmonary embolism, or pulmonary embolism in transit. They have also been associated with arrhythmogenic right ventricular dysplasia, Bechet's disease, metastatic disease, and trauma [28].
In addition to intracardiac thrombus formation, the development of left ventricular pseudoaneurysm as a complication of a large myocardial infarction may present as a cardiac mass on echocardiography and can be easily distinguished using cardiac CT (Fig. 9).

\section{Pericardial Cyst}

Pericardial cysts are benign, congenital lesions that account for $7 \%$ of all mediastinal tumors [35]. Over $75 \%$ are located within the cardiophrenic spaces, the majority of which have a right-sided predominance. This anatomic location helps to distinguish pericardial
Fig. 9 Left ventricular pseudoaneurysm. Contrast cardiac CT demonstrating a large pseudoaneurysm (Ps) of the left ventricular (LV) basal lateral wall as seen in oblique (a-c) and volume rendered (d) reformations. The patient had a history of a remote myocardial infarction that was complicated by cardiac tamponade due to left ventricular rupture. Note: thrombus (*) is visualized within the pseudoaneurysm and the rim of the pseudoaneurysm is calcified. LA, left atrium; $\mathrm{Cx}$, circumflex coronary artery. * Reproduced with permission from [34]
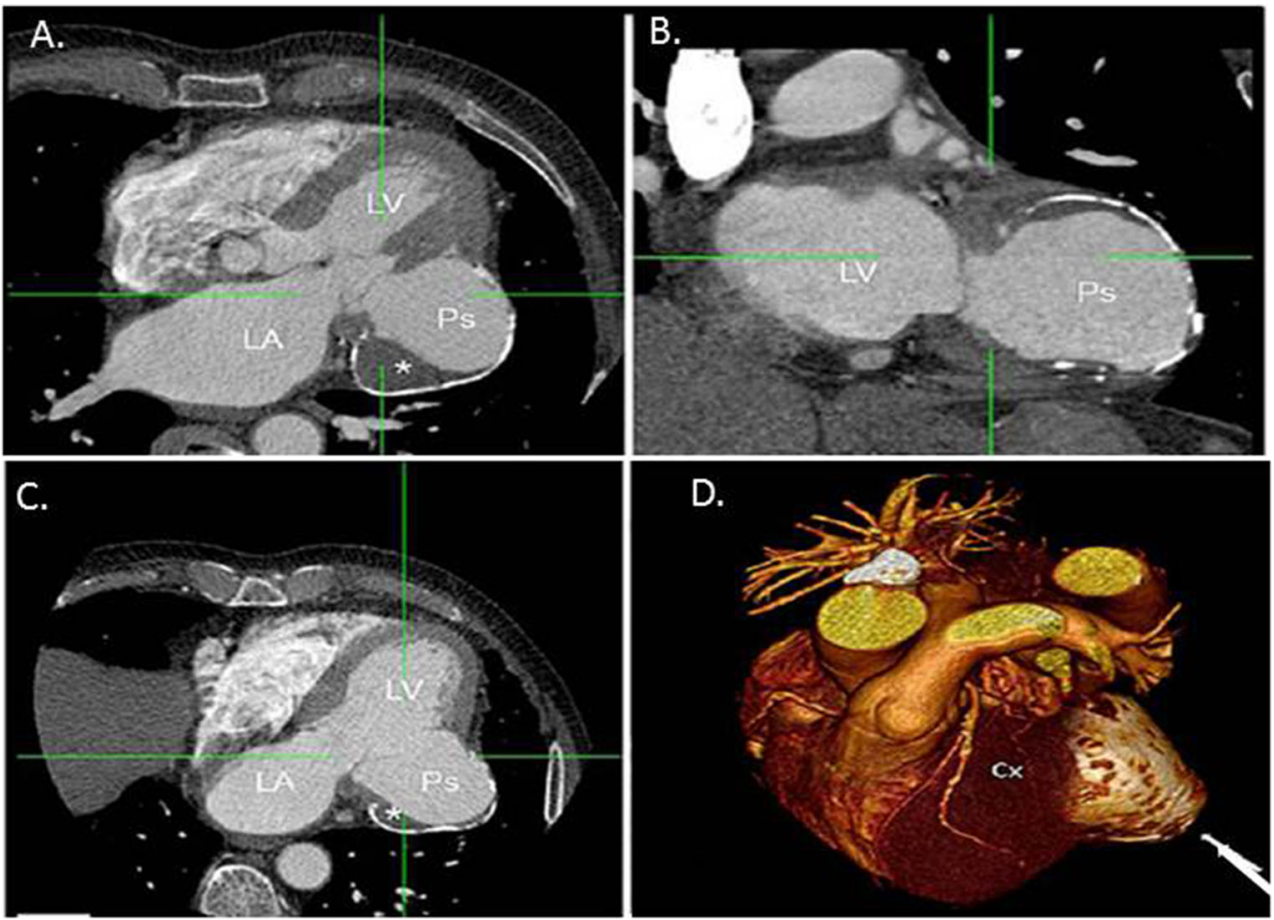
Fig. 10 Pericardial cyst. (left) anterior chest X-ray suggestive of a mass at the right costophrenic angle. (right) contrast cardiac CT demonstrating that the mass correlates to a homogenous cyst in the right cardiophrenic angle most consistent with a benign pericardial cyst
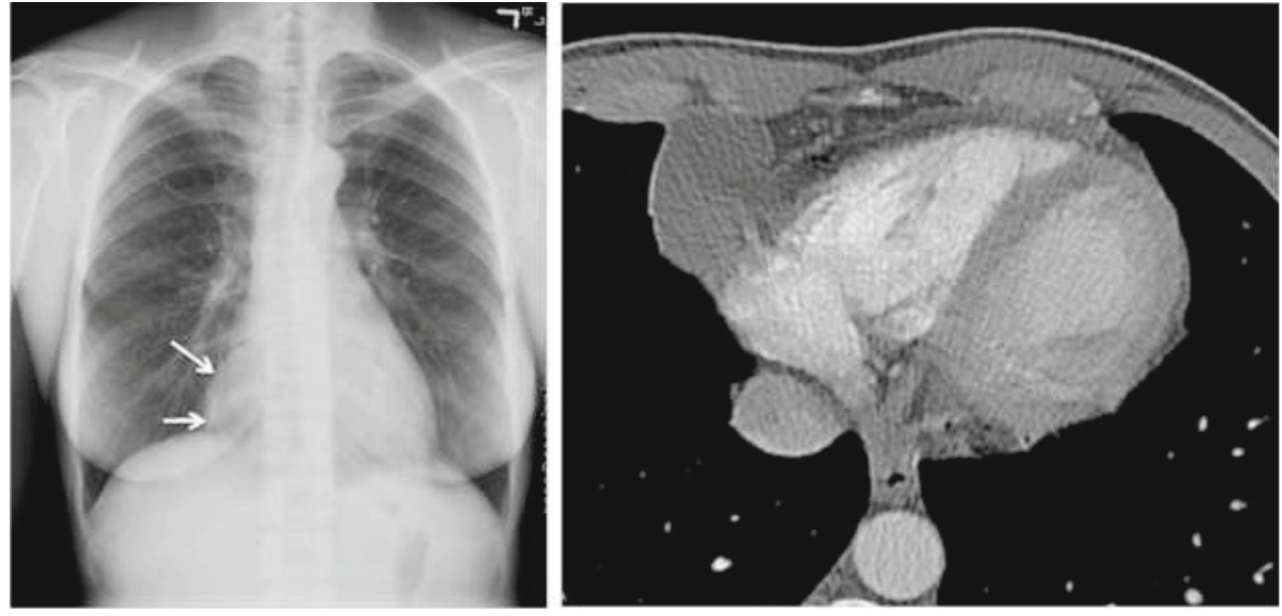

cysts from other similar findings to include bronchogenic cysts, thymic cysts, and cardiac teratomas. Additionally, with pericardial cysts, there is no connection with the pericardial space, unlike that of pericardial diverticulae. On cardiac CT, pericardial cysts are thin- walled structures that are sharply demarcated, lack septae, and have a homogenous appearance (Fig. 10). They are non-enhancing lesions with intravenous contrast administration and have attenuation similar to water $(-10$ to $20 \mathrm{HU})$ [36].
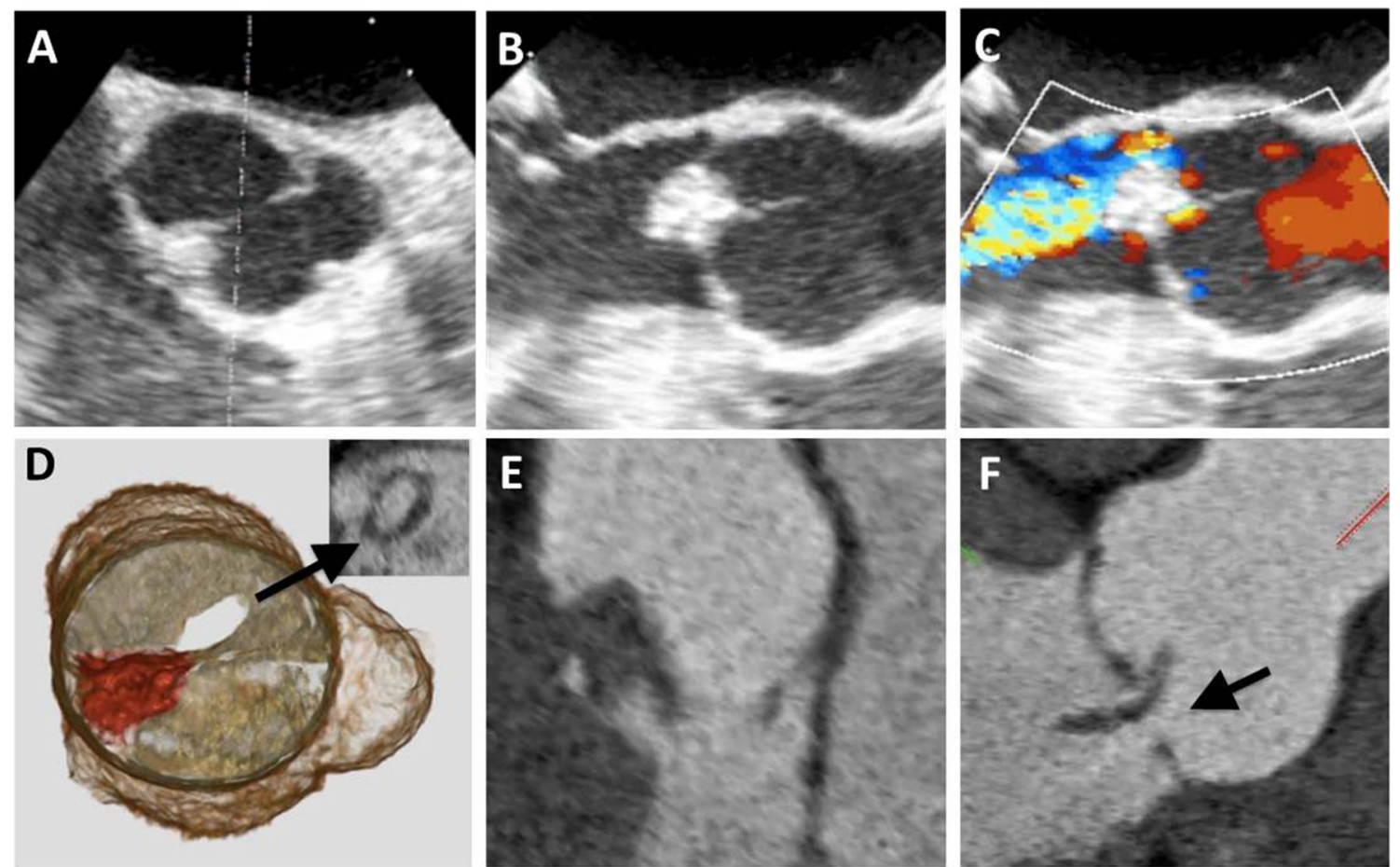

Fig. 11 Valvular vegetation. Transesophageal echocardiogram (TEE), mid-esophageal short-axis (a) and long axis (b) views at peak diastole demonstrating a bicuspid aortic valve with fusion of the left and right coronary cusps and a $1.5 \times 1.0 \mathrm{~cm}$ mobile echodensity attached to the right and non-coronary cusp. TEE long axis view with color Doppler demonstrates severe, eccentric aortic insufficiency (c). Cardiac CT 3D image reconstruction of a closed bicuspid aortic valve demonstrates the relationship of the mass (depicted in red) at the right and the non-coronary cusp with perforation of the non-coronary cusp (arrow) reproduced on 2D CCT short axis view (insert) with a regurgitant orifice area measuring $0.8 \mathrm{~mm}^{2}$ consistent with severe aortic regurgitation (d). Orthogonal 2D CCT 3-chamber views demonstrate a hypodense, irregular mobile mass (e) with associated flail leaflet and valve perforation (arrow) (f) 
Fig. 12 Crista terminalis. Serial axial images (a-d) of a coronary CT angiography study demonstrating the normal appearance of the crista terminalis (arrow) extending in the craniocaudal region in the posterior wall of the right atrium
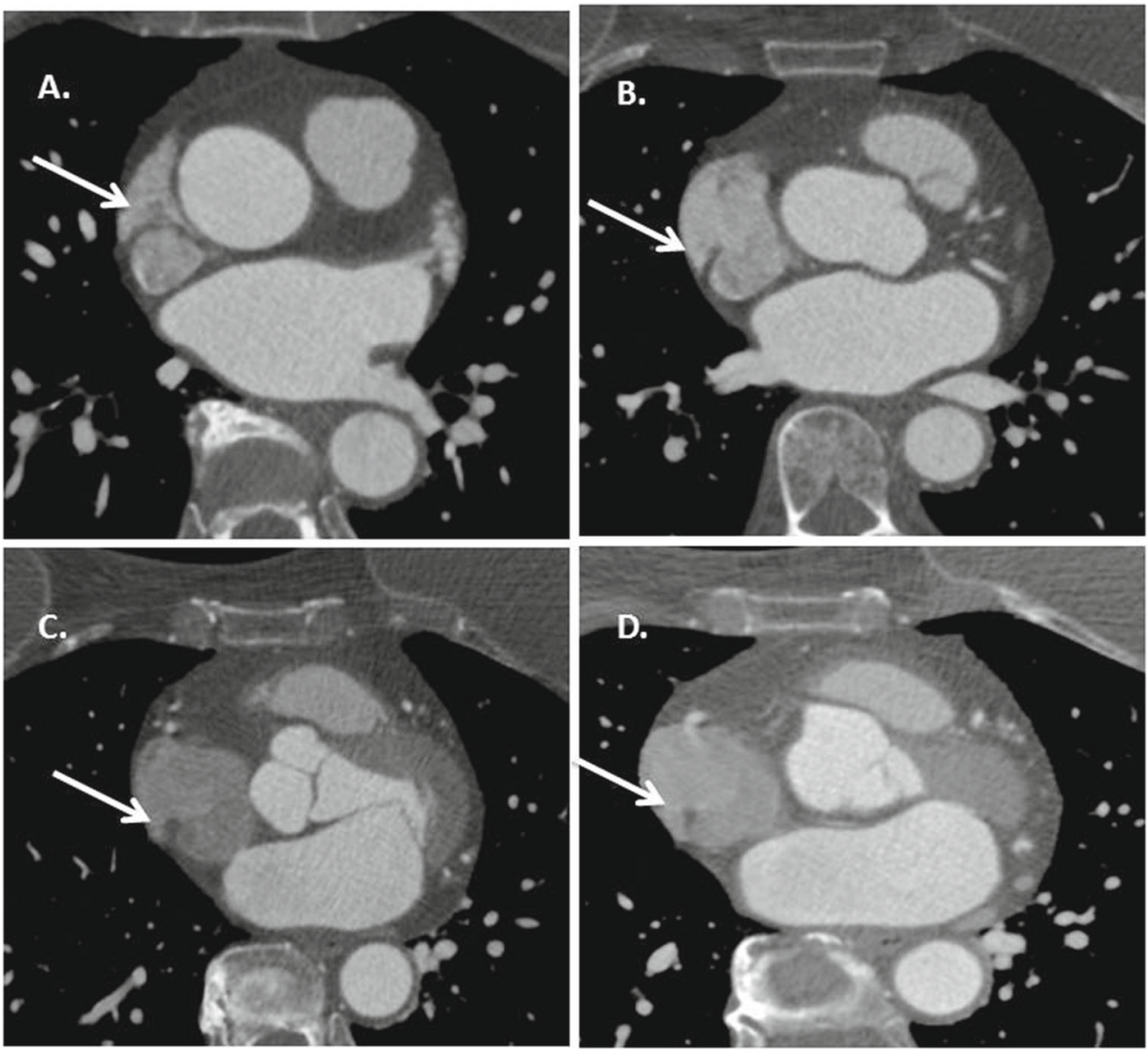

\section{Valvular Vegetation}

Cardiac CT has demonstrated to be highly accurate in identifying valvular vegetations, with a sensitivity of $97 \%$ and specificity of $88 \%$ as compared to transesophageal echocardiography [37]. On cardiac CT, vegetations appear as lowattenuation masses usually involving the valve leaflet free edge (Fig. 11). As a result, vegetations can lead to valvular destruction and/or dysfunction [38] and cardiac CT is particularly helpful in identifying perivalvular complications, such as perivalvular abscess formation, valve perforation, aortic pseudoaneurysms or extracardiac manifestations, such as septic emboli to the lung parenchyma.

\section{Crista Terminalis}

The crista terminalis is a common mimicker of cardiac tumors when seen on cardiac $\mathrm{CT}$ and can be mistaken for a right atrial mass or thrombus. The crista terminalis is a smooth-surfaced, linear fibromuscular structure, with a vertical orientation and crescent shape running along the posterior wall of the right atrium from the superior vena cava to the inferior vena cava (Fig. 12). It separates the smooth sinus venosus portion of the right atrium from the trabeculated right atrial tissue and right atrial appendage. Regression is inconsistent among individuals resulting in a significant variation in the degree of fibromuscular extension. It is most notable when triphasic contrast injection protocols are used for cardiac CT. It can be distinguished on cardiac CT as a focal, low-density attenuation similar to fat.

\section{Conclusion}

In summary, cardiac CT can provide useful anatomic and functional information as an adjunct to echocardiography and MR in the evaluation of cardiac masses. With high spatial and contrast resolution, fast acquisition times, and the capability to identify calcification and fat, cardiac CT can serve as an ideal alternative to MR imaging, especially in patients with contraindications. Furthermore, cardiac CT may have specific advantages in defining the cardiovascular extent of the mass and excluding coronary artery disease prior to surgical intervention. With the continued, widespread utilization of cardiac $\mathrm{CT}$, it is important to accurately distinguish cardiac masses in order to provide optimal medical management. 


\section{Compliance with Ethics Guidelines}

Conflict of Interest David Kassop, Michael S. Donovan, Michael K. Cheezum, Binh T. Nguyen, Neil B. Gambill, Ron Blankstein, and Todd C. Villines declare that they have no conflict of interest.

Human and Animal Rights and Informed Consent This article does not contain any studies with human or animal subjects performed by any of the authors.

Open Access This article is distributed under the terms of the Creative Commons Attribution License which permits any use, distribution, and reproduction in any medium, provided the original author(s) and the source are credited.

\section{References}

Papers of particular interest, published recently, have been highlighted as:

- Of importance

•. Of major importance

1. Burke A, Vermani R. Tumors of the heart and great vessels. Atlas of Tumor Pathology. 3rd Series, Fascicle 16. Washington, DC, Armed Forces Institute of Pathology, 1996.

2. Grebenc ML, Rosado-de-Christenson ML, Burke AP, et al. Primary cardiac and pericardial neoplasms: Radiologic-pathologic correlation. Radiographics. 2000;20:1073-103.

3. Best AK, Dobson RL, Ahmad AR. Best cases from the AFIP: Cardiac angiosarcoma. Radiographics. 2003;23:S141-5.

4. Buckley O, Madan R, Kwong R, et al. Cardiac masses, part 1: Imaging strategies and technical considerations. Am J Roentgenol. 2011;197:W837-41. Thorough review of multimodality cardiovascular imaging for cardiac masses.

5. Hendel RC, Patel MR, Kramer CM, et al. ACCF/ACR/SCCT/ SCMR/ASNC/NASCI/SCAI/SIR 2006 appropriateness criteria for cardiac computed tomography and cardiac magnetic resonance imaging: a report of the American College of Cardiology Foundation Quality Strategic Directions Committee Appropriateness Criteria Working Group, American College of Radiology, Society of Cardiovascular Computed Tomography, Society for Cardiovascular Magnetic Resonance, American Society of Nuclear Cardiology, North American Society for Cardiac Imaging, Society for Cardiovascular Angiography and Interventions, and Society of Interventional Radiology. J Am Coll Cardiol. 2006;48:1475-97.

6. Taylor AJ, Cerqueira M, Hodgson JM, et al. ACCF/SCCT/ACR/ AHA/ASE/ASNC/NASCI/SCAI/SCMR 2010 Appropriate Use Criteria for Cardiac Computed Tomography. A Report of the American College of Cardiology Foundation Appropriate Use Criteria Task Force, the Society of Cardiovascular Computed Tomography, the American College of Radiology, the American Heart Association, the American Society of Echocardiography, the American Society of Nuclear Cardiology, the North American Society for Cardiovascular Imaging, the Society for Cardiovascular Angiography and Interventions, and the Society for Cardiovascular Magnetic Resonance. J Cardiovasc Comput Tomogr. 2010;4:407-33.

7.• Klein AL, Abbara S, Agler DA, et al. American Society of Echocardiography clinical recommendations for multimodality cardiovascular imaging of patients with pericardial disease: endorsed by the Society for Cardiovascular Magnetic Resonance and Society of Cardiovascular Computed Tomography. J Am Soc Echocardiogr.
2013;26:965-1012. New evidence-based guidelines integrating CCT in the assessment of pericardial disease.

8. O'Donnell DH, Abbara S, Chaithiraphan V, et al. Cardiac tumors: Optimal cardiac MR sequences and spectrum of imaging appearances. Am J Roentgenol. 2009;193:377-87.

9. Rahbar K, Seifarth H, Schäfers M, et al. Differentiation of malignant and benign cardiac tumors using ${ }^{18} \mathrm{~F}$-FDG PET/CT. J Nucl Med. 2012;53:856-63. Restrospective study aimed to evaluate the diagnostic value of ${ }^{18}$ F-FDG PET/CT in the noninvasive preoperative determination of malignant cardiac tumors and metastases.

10. Araoz PA, Mulvagh SL, Tazelaar HD, et al. CT and MR imaging of benign primary cardiac neoplasms with echocardiographic correlation. Radiographics. 2000;20:1303-19.

11. Grebenc ML, Rosado-De-Christenson ML, Green CE, et al. Cardiac myxoma: imaging features in 83 patients. Radiographics. 2002;22:673-89.

12. Shetty Roy AN, Radin M, Sarabi D, et al. Familial recurrent atrial myxoma: Carney's complex. Clin Cardiol. 2011;34:83-6.

13. Carney JA. Differences between nonfamilial and familial cardiac myxoma. Am J Surg Pathol. 1985;9:53-5.

14. Howard RA, Aldea GS, Shapira OM, et al. Papillary fibroelastoma: Increasing recognition of a surgical disease. Ann Thorac Surg. 1999;68:1881-5.

15. Edwards FH, Hale D, Cohen A, et al. Primary cardiac valve tumors. Ann Thorac Surg. 1991;52:1127-31.

16. Taori K, Jawale R, Sanyal R, et al. Intrapericardial teratoma diagnosed on CT. J Thorac Imaging. 2007;22:185-7.

17. Rojas CA, Jaimes CE, El-Sherief AH, et al. Cardiac CT of non-shunt pathology of the interatrial septum. J Cardiovasc Comput Tomogr. 2011;5:93-100.

18. Goldberg AD, Blankstein R, Padera RF. Tumors metastatic to the heart. Circulation. 2013;128:1790-4. In-depth review of metastatic tumors to the heart.

19. Rao U, Curtin J, Ryding A. Primary angiosarcoma of the heart. Heart. 2013;99:1878-9.

20. Tang K, Shiag QL, Zhor QC, et al. Primary cardiac angiosarcoma with spontaneous ruptures of the right atrium and right coronary artery. Echocardiography. 2013;30:E156-60.

21. Riles E, Gupta S, Wang DD, et al. Primary cardiac angiosarcoma: A diagnostic challenge in a young man with recurrent pericardial effusions. Exp Clin Cardiol. 2012;17:39-42.

22. Villacampa VM, Villarreal M, Ros LH, et al. Cardiac rhabdomyosarcoma: Diagnosis by MR imaging. Eur Radiol. 1999;9:634-7.

23. Sparrow PJ, Kurian JB, Jones TR, et al. MR imaging of cardiac tumors. Radiographics. 2005;25:1255-76.

24. Heyer CM, Kagel T, Lemburg SP, et al. Lipomatous hypertrophy of the interatrial septum: a prospective study of incidence, imaging findings, and clinical symptoms. Chest. 2003;124:2068-73.

25. Abdul-Jawad O, Barrabes JA, Figueras J, et al. Severe thrombocytopenia complicating giant left atrial rhabdomyosarcoma. Int $\mathrm{J}$ Cardiol. 2011;150:e15-6.

26. Cheezum MK, Jezior MR, Carbonaro S, Villines TC. Lipomatous hypertrophy presenting as superior vena cava syndrome. J Cardiovasc Comput Tomogr. 2014.

27. Shirani J, Roberts WC. Clinical, electrocardiographic, and morphologic features of massive fatty deposits ("lipomatous hypertrophy") in the atrial septum. J Am Coll Cardiol. 1993;22:226-38.

28. Kim DH, Choi S, Choi JA, et al. Various findings of cardiac thrombi on MDCT and MRI. J Comput Assist Tomogr. 2006;30:572-7.

29. Bittencourt MS, Achenbach S, Marwan M, et al. Left ventricular thrombus attenuation characterization in cardiac computed tomography angiography. J Cardiovasc Comput Tomogr. 2012;6:121-6. Retrospective study analyzing left ventricular thrombus characteristics on CCT.

30. Hur J, Kim YH, Lee HJ, et al. Dual-enhanced cardiac CT for detection of left atrial appendage thrombus in patients with stroke: a prospective 
comparison study with transesophageal echocardiography. Stroke. 2011;42:2471-7. Prospective study comparing CCT left atrial appendage thrombus detection with transesophageal echocardiogram; findings demonstrate a sensitive, noninvasive alternative.

31. Hur J, Pak HN, Kim YH, et al. Dual-enhancement cardiac computed tomography for assessing left atrial thrombus and pulmonary veins before radiofrequency catheter ablation for atrial fibrillation. Am J Cardiol. 2013;112:238-44.

32. Patel A, Au E, Donegan K, et al. Multi-detector row computed tomography for identification of left atrial appendage filling defects in patients undergoing pulmonary vein isolation for treatment of atrial fibrillation; comparison with transesophageal echocardiography. Heart Rhythm. 2008;5:253-60.

33. Scheffel H, Baumueller S, Stolzmann P, et al. Atrial myxomas and thrombi: comparison of imaging features on CT. Am J Roentgenol. 2009;192:639-45.
34. Della Roca DG, Forleo GB, Stazi CA, et al. Massive Left Ventricular Pseudoaneurysm 20 Years After Acute Myocardial Infarction. J Am Coll Cardiol. 2013;62:e523

35. Patel J, Park C, Michaels J, et al. Pericardial Cyst: Case reports and a literature review. Echocardiography. 2004;21: 269-72.

36. Yared K, Baggish A, Picard M, et al. Multimodality imaging of pericardial diseases. J Am Coll Cardiol Img. 2010;3:65060.

37. Feuchtner GM, Stolzmann P, Dichtl W, et al. Multislice Computed Tomography in Infective Endocarditis: Comparison With Transesophageal Echocardiography and Intraoperative Findings. J Am Coll Cardiol. 2009;53:436-44.

38. Ketelsen D, Fishman EK, Claussen CD, et al. Computed tomography evaluation of cardiac valves: a review. Radiol Clin N Am. 2010;48:783-97. 